\title{
On the function of redfronted lemur's close calls
}

\author{
Femke J. Pflüger · Claudia Fichtel
}

Received: 29 September 2011 / Accepted: 13 April 2012/Published online: 10 May 2012

(C) The Author(s) 2012. This article is published with open access at Springerlink.com

\begin{abstract}
In order to maintain group cohesion, many social mammals and birds regularly produce close calls. In some primate species, close calls appear to have a dual function: calls addressed at a broad class of targets serve to maintain group cohesion, whereas the same calls directed at a specific target serve to regulate subsequent social interactions. Redfronted lemurs (Eulemur rufifrons) produce different types of close calls: grunts, long grunts, hoos and meows. In order to study the function of these calls, we conducted focal observations and vocal recordings from eight adult males and females out of four social groups in Kirindy Forest, Western Madagascar. Redfronted lemurs produce long grunts, hoos and meows at relatively low rates during foraging, resting or group movements, respectively. Grunts were given most often and more or less constantly during foraging and traveling. Calling rate increased when the risk of separation increased and may thus promote group cohesion. Grunts given during approaches of other group members resulted more often in friendly interactions than approaches that were not accompanied by a grunt. Thus, redfronted lemurs produce specific but also generic contact calls, whereas the latter calls have a dual function that varies depending on the addressed audience: they act as an auditory beacon to maintain group cohesion and serve as signals of benign intent to avoid costly conflicts and facilitating social interactions.
\end{abstract}

F. J. Pflüger $(\bowtie) \cdot$ C. Fichtel

Behavioral Ecology and Sociobiology Unit,

German Primate Center, Kellnerweg 4,

37077 Göttingen, Germany

e-mail: femke_pflueger@gmx.de

F. J. Pflüger · C. Fichtel

Courant Research Centre "Evolution of Social Behaviour",

University of Göttingen, Göttingen, Germany
Keywords Eulemur rufifrons - Contact calls · Group cohesion - Social interaction - Social cognition

\section{Introduction}

Many animals are organized into permanent social groups. Living in groups has many benefits, including reduced individual predation risk, joint resource defense, cooperative foraging, shared vigilance and information transfer (Alexander 1974; Bertram 1978; van Schaik 1983; Zemel and Lubin 1995). However, living in a group also results in inter-individual conflicts and costs, such as competition over resources and mates or increased pathogen transmission. These factors limit the size of groups and act as a centrifugal force on group cohesion (Alexander 1974; Bertram 1978). In order to maintain group cohesion and social stability despite these conflicts, individuals need to regulate spacing between group members and employ mechanisms to reduce conflicts (Aureli and de Waal 2000; Radford and Ridley 2008).

Many animals produce vocal signals that appear to be involved in the maintenance of group cohesion and decision-making processes before collective movements (Boinski and Garber 2000; Fichtel and Manser 2010). Several species produce the so-called close calls when traveling, foraging and resting (Struhsaker 1967; Boinski and Garber 2000; Rendall et al. 1999; Radford 2004; Trillmich et al. 2004; Koda et al. 2008). These calls may serve as a 'location marker' to announce the caller's spatial position but also to regulate spacing between group members. For example, group-living pied babblers (Turdoides bicolor) produce chucks during foraging to maintain cohesion, but also to regulate spacing of potential competitors (Radford and Ridley 2008). 
In primates, many species produce long distance calls to regulate intra- and inter-group spacing over longer distances but also close distance calls (Snowdon et al. 1983; Biben 1993; Cheney and Seyfarth 1996; Fichtel and Kappeler 2002; Digweed et al. 2007). Close distance calls appear to be addressed at several recipients and in many species such as golden lion tamarins (Leonthopithicus rosalia), white-faced capuchin monkeys (Cebus capucinus) and Japanese macaques (Macaca fuscata) the rate of calling increased when the risk of becoming separated from the group was high as during foraging or moving or in dense habitats (Boinski 1993; Boinski et al. 1994; Koda et al. 2008; Ey et al. 2009). Interestingly, the function of the same close calls seems to vary when they are addressed at a specific target. For example, baboons grunt when they move and forage but also when approaching mothers attempting to inspect or handle their young infants (Rendall et al. 1999). The likelihood of a subsequent peaceful interaction was usually higher when approaches were accompanied by grunts. Thus, during social interactions, baboon grunts seem to facilitate subsequent peaceful behavior among interaction partners (Cheney et al. 1995).

A similar function of close calls has been suggested in other species such as stumptailed macaques (M. arctoides; Bauers 1993) and Japanese macaques (Masataka 1989). In rhesus macaques ( $M$. mulatta), the likelihood of an aggressive interaction was directly associated with the use of grunts and girneys. Females were much less likely to initiate aggression when approaches at lower ranking females were accompanied with contact calls than when they remained silent (Silk et al. 2000). In this context, these calls have been suggested to function as generic commitments signaling what animals will do next (Silk 2002; but see Whitham et al. 2007). Thus, close calls appear to have depending on the audience at which they are addressed a dual function: they may either function to maintain group cohesion or to regulate social interactions (Fichtel and Manser 2010).

While most previous studies of close calls were performed on anthropoid primates, data from a greater variety of taxa could provide important comparative information for a more comprehensive understanding of the function of close calls in group-living primates. Lemuriformes, which are relatively small-brained (Barton 1996), form an independent primate radiation (Tattersall 1982) and represent the most primitive group-living primates (Bearder 1987; Richard 1987). Furthermore, group living in Malagasy primates evolved at least twice independently (Kappeler 1999). During millions of years of isolation, they converged with other group-living primates only in the most fundamental ways, but deviate in several aspects of their social organization, such as group size or sex ratio (van Schaik and Kappeler 1993; Kappeler 1997; Erhart and
Overdorff 2008). Thus, a broad comparative perspective including the best living models of the earliest gregarious primates can enrich reconstructions of primate social behavior and cognition (Fichtel and Kappeler 2010).

Redfronted lemurs (Eulemur rufifrons) are group-living lemurs with a complex vocal repertoire. They produce several calls during group movements, foraging but also during social interactions as well as alarm calls (Pereira and Kappeler 1997; Fichtel and Kappeler 2002). In particular, grunts are more or less constantly produced while moving, foraging and during social interactions (Pereira and Kappeler 1997) and may, thus, serve to maintain group cohesion and to regulate social interactions. However, they also produce other calls such as hoos, meows and long grunts while resting and moving, indicating that redfronted lemurs may use several types of close calls.

In order to examine the function of these calls, that is grunts, long grunts, meows and hoos, we investigated their usage in four social groups of wild redfronted lemurs in Kirindy forest, Western Madagascar. If these calls serve to maintain cohesion, we predicted that they should be produced more often when the risk of separation increases and the group is widespread, exhibiting low cohesion as during foraging and moving. If these calls also serve to regulate social interactions, we predicted that they are also produced during social interactions and that the likelihood of aggression decreases when approaches are accompanied by a close call.

\section{Materials and methods}

Study area and subjects

In this study, we observed 16 adult individuals out of four groups of redfronted lemurs (E. rufifrons) in Kirindy forest, Western Madagascar (Kappeler and Fichtel 2012a). Because groups of redfronted lemurs consist on average of 2-3 females (Kappeler and Fichtel 2012b), we chose two adult females and two adult males in each group as focal animals to have a balanced sample size. As part of an ongoing long-term study, all animals are individually marked with nylon collars or radio transmitters.

\section{Data collection}

Focal animals (eight females, eight males) were observed using continuous sampling (Altmann 1974) during 30-min observation sessions. Data collection included continuous recordings of the focal animal's vocalizations and a documentation of the general activity such as group movements between food patches and resting sites (GM), locomotion during foraging or approaching conspecifics 
(LO), feeding (FE), resting (RE) and resting in social interactions (SI) (see Table 1 for definitions). Recordings of vocalizations were made with a Marantz PMD $670 \mathrm{CF}$ Recorder and a Sennheiser ME 80 directional microphone.

Additionally, all social interactions between the focal animal and another group member were noted. During approaches, we recorded whether focal animals produced contact calls when they entered within a $3 \mathrm{~m}$ radius of the targeted animal. We also documented whether the target showed affiliative or agonistic behavior toward the approaching individual.

\section{Analysis of call rates}

Vocalizations were recorded for $100 \mathrm{~h}$ and were digitized at a sampling rate of $48 \mathrm{kHz}$ (16-bit resolution) in Avisoft-SASLab Pro software (Avisoft Bioacoustics). Several recordings were discarded due to high levels of background noises produced by cicadas, reducing the recording duration to $57 \mathrm{~h}$. This resulted in an unbalanced data set per individual. In order to have an equal observation time of about $4 \mathrm{~h}$ for each focal animal, only 12 (six adult males and six adult females) animals were included in the analysis of call rates. Only calls of high-quality recordings were included in the analysis, resulting in 16.425 calls. We categorized vocalizations as grunts $(N=14,825)$, long grunts $(N=303)$, hoos $(N=396)$ and meows $(N=120$; Fig. 1$)$. Calls given in response to predators, during aggressive interactions, or between group communication, that is chucks, woofs, chutter and croaks (Fichtel and Kappeler 2002), were summarized as other calls $(N=907)$ and were only included in the comparison of call rates across call types. For each individual, we calculated the call rate of each call type across contexts. To compare call rates across call types and the use of certain call types across activities, we calculated generalized linear mixed effects models (GLMM) and linear mixed effects models (LMM) with square-root transformed response variables and REML estimation (Zuur et al. 2009; Bolker et al. 2009). The response variable was the rate of the different call types. Activity (i.e., group movement, feeding, locomotion, resting, social resting) and sex were included as fixed factor, and individuals nested within social groups were included as random factors to account for non-independence of repeated measurements of individuals (e.g., Zuur et al. 2009). We used maximum likelihood ratio tests to test the final model with fixed factors against the null model including only the intercept and random factors (Faraway 2006). For the LMM, we used Markov chain Monte Carlo methods to generate $p$ values (Bates et al. 2008). Tukey post hoc comparisons were conducted with the multcomp package (function glht in R; Hothorn et al. 2008).

\section{Analysis of social interactions}

For the analysis of social interactions, we included interactions between all adult focal individuals $(N=16)$ and their adult or subadult group mates (defined as a dyad). In the four social groups, 82 of dyads were possible, but only 55 of them occurred during observation. In order to test the hypothesis that close calls serve to mediate social interactions, we used a multiple logistic regression with binomial error (link = logit; e.g., Bolker et al. 2009). The affiliative or agonistic outcome of an approach was the dichotomous response variable. As fixed factor we used whether the approach was accompanied with a grunt or not. To exclude the possibility that results were influenced by other factors besides the production of grunts, sex (three levels: dyads of two males (mm), two females (ff) or a

Table 1 Definitions of behavioral patterns modified from Pereira and Kappeler (1997)

\begin{tabular}{|c|c|}
\hline $\begin{array}{l}\text { Group } \\
\text { movements }\end{array}$ & $\begin{array}{l}\text { Movements of the whole group on the ground or in trees for at least } 4 \text { min or at least } 15 \mathrm{~m} \text { between food patches and resting } \\
\text { sites (Pyritz et al. 2010) }\end{array}$ \\
\hline Locomotion & $\begin{array}{l}\text { Short distance movements while foraging, approaching conspecifics or departure from them. Short distance movements were } \\
\text { defined as movements lasting between } 10 \mathrm{~s} \text { and } 4 \mathrm{~min}\end{array}$ \\
\hline Feeding & $\begin{array}{l}\text { Searching with nose over ground or terminal branches, manually grasping, biting or chewing potential food items, including } \\
\text { feeding movement for less than } 10 \mathrm{~s}\end{array}$ \\
\hline Resting & Individual remains inactive for at least $1 \mathrm{~min}$ \\
\hline Social resting & Resting in body contact or huddling with one or more group members for at least $1 \mathrm{~min}$ \\
\hline Approach & $\begin{array}{l}\text { An animal moved from beyond a distance of at least } 3 \mathrm{~m} \text { to a distance of less than } 50 \mathrm{~cm} \text { to a targeted individual, including } \\
\text { subsequent affiliative or agonistic interactions between the animals }\end{array}$ \\
\hline $\begin{array}{l}\text { Affiliative } \\
\text { behavior }\end{array}$ & $\begin{array}{l}\text { Grooming was defined as repeated strokes over partner's pelage using the toothcomb and/or tongue. Two animals huddle } \\
\text { together when at least two animals rest in a hunched position, keeping less than one-third of body-to-body contact on the } \\
\text { resting partner. Sitting near was defined as resting within } 0.3 \mathrm{~m} \text { of a group member }\end{array}$ \\
\hline $\begin{array}{l}\text { Agonistic } \\
\text { behavior }\end{array}$ & $\begin{array}{l}\text { Submission was defined as self-displacement when the target immediately moved for more than } 1 \mathrm{~m} \text { away from the } \\
\text { approaching animal }\end{array}$ \\
\hline & Aggressions included biting, cuffing, grabbing and chasing \\
\hline
\end{tabular}




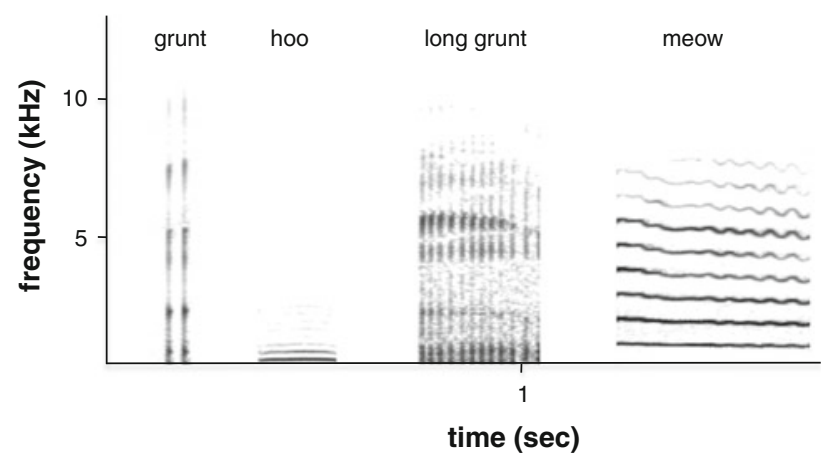

Fig. 1 Spectrograms of a grunt, hoo, long grunt and meow. All spectrograms were generated in Avisoft-SASLabPro Software (Avisoft Bioacoustics; frequency resolution: window length $=200 \mathrm{~ms}$, bandwidth $=70 \mathrm{~Hz}$, resolution: $47 \mathrm{~Hz}$, temporal resolution: overlap $=87.5 \%, 1 /$ bandwidth $=14.2 \mathrm{~ms}$, resolution $=2.67 \mathrm{~ms}$ )

male and a female (mf), age of the approaching animal (adult or subadult) and kin were also included as fixed factors. Since repeated observations of the same dyad do not provide independent information, dyads nested within groups were defined as a random factor in the model (e.g., Zuur et al. 2009). Statistical tests were computed in $\mathrm{R}$ 2.13.0 (R Developmental Core Team 2011).

\section{Results}

Usage of call types across contexts

Grunts were the most frequently emitted call type and were more often produced than all other call types (Fig. 2; Table 2, GLMM, $\left.\chi^{2}=15,599, d f=4, p<0.001\right)$. In comparison with grunts hoos, long grunts, meows and other calls were produced at relatively low rates. Call rates differed between other calls and hoos, long grunts and meows and between hoos and meows as well as between long grunts and meows (Fig. 2).

Grunts were significantly more often produced during locomotion and group movements, but less often emitted during feeding, resting and social resting (Fig. 3a; Table 2, LMM, $\left.\chi^{2}=301.76, d f=5, p<0.001\right)$. The grunt rate decreased from locomotion over group movements, feeding and social resting to resting. Sex did not influence grunt rates.

Hoos were given significantly more often during resting than locomotion and feeding, but hoo rates differed not between group movements, feeding and social resting (Fig. 3b; Table 2, LMM, $\chi^{2}=2106.4, d f=5, p<0.001$ ). Sex had no effect on hoo rates.

Meows were significantly more often produced during group movements than in other contexts (Fig. 3c; Table 2, LMM, $\left.\chi^{2}=2818.4, d f=5, p<0.001\right)$. The rate of meows was not influenced by sex.
Long grunts were given significantly more often during locomotion and group movements than during feeding, but long grunt rates differed not between feeding, social resting and resting (Fig. 3d; Table 2, LMM, $\chi^{2}=2057.8, d f=5$, $p<0.001$ ). Sex had a significant effect on the rate of long grunts with males producing long grunts more often than females (Table 2).

\section{Social interactions}

We observed 172 social interactions. In 152 of these, the approaching animal grunted. The probability of an affiliative interaction was higher $(92 \%)$ when the approaching animal produced grunts than without producing grunts (30\%) (Table 2; Fig. 4). Age also had an effect on the outcome of an approach with approaching adults receiving aggression less often (9\% of approaches) than subadults (28\% of approaches) (Table 2), but the interaction between grunting and age was not significant. Other fixed factors like sex and kin did not influence the behavior of the receiver (Table 2).

\section{Discussion}

In this study, we investigated the function of redfronted lemur's close calls: grunts, long grunts, hoos and meows. The grunt was the most often produced call type. Redfronted lemurs produced them more or less constantly in all contexts, but most often in contexts when the risk of separation from the group was high. Grunts were also produced during social interactions and seem to facilitate peaceful interactions. Thus, grunts appear to have a dual function and may serve as a location marker to maintain group cohesion but also as a signal of benign intent. Hoos, meows and long grunts were produced at relatively low rates in comparison with grunts but, interestingly, in rather specific contexts: hoos are given most often during resting, meows during group movements and long grunts during locomotion and group movements. Thus, redfronted lemurs use a combination of generic and context-specific close calls.

Dual function of grunts: maintenance of cohesion and signals of benign intent

According to the definition of Rendall et al. (2000), redfronted lemurs' grunts can be classified as contact calls because they are relatively quite calls given at high rates while the group moves or forages and the risk of becoming separated is therefore high. Grunts were the most frequently produced call type and their rate increased from resting over feeding to locomotion. These results are in line with the usage of contact calls in birds and other anthropoid 
Table 2 Estimates, SE and $p$ values of the models for (a) call rates (b) grunt rates, (c) hoo rates, (d) meow rates (e) long grunt rates and (f) social interactions ( $\mathrm{f}=$ female, $\mathrm{m}=$ males)

\begin{tabular}{|c|c|c|c|c|c|}
\hline Response variable & Random factor & Fixed factors & Estimate & SE & $p$ value \\
\hline \multirow[t]{5}{*}{ (a) Call rates } & \multirow[t]{5}{*}{ ID nested in group } & Intercept & -0.98 & 0.13 & $<0.001$ \\
\hline & & Grunt & 3.13 & 0.06 & $<0.001$ \\
\hline & & Hoo & -1.83 & 0.13 & $<0.001$ \\
\hline & & Long grunt & -1.11 & 0.13 & $<0.001$ \\
\hline & & Meow & -2.38 & 0.22 & $<0.001$ \\
\hline \multirow[t]{6}{*}{ (b) Grunt rate } & \multirow[t]{6}{*}{ ID nested in group } & Intercept & 2.23 & 0.23 & $<0.001$ \\
\hline & & Group movements & 1.49 & 0.21 & $<0.001$ \\
\hline & & Locomotion & 2.29 & 0.17 & $<0.001$ \\
\hline & & Resting & -0.64 & 0.15 & $<0.001$ \\
\hline & & Social resting & -0.50 & 0.21 & $<0.05$ \\
\hline & & Sex & -0.33 & 0.29 & 0.26 \\
\hline \multirow[t]{6}{*}{ (c) Hoo rate } & \multirow[t]{6}{*}{ ID nested in group } & Intercept & 0.04 & 0.03 & 0.23 \\
\hline & & Group movements & 0.13 & 0.05 & $<0.01$ \\
\hline & & Locomotion & 0.07 & 0.04 & 0.07 \\
\hline & & Resting & 0.19 & 0.04 & $<0.001$ \\
\hline & & Social resting & 0.08 & 0.05 & 0.12 \\
\hline & & Sex & -0.03 & 0.03 & 0.32 \\
\hline \multirow[t]{6}{*}{ (d) Meow rate } & \multirow[t]{6}{*}{ ID nested in group } & Intercept & 0.02 & 0.03 & 0.39 \\
\hline & & Group movements & 0.18 & 0.03 & $<0.001$ \\
\hline & & Locomotion & 0.01 & 0.02 & 0.61 \\
\hline & & Resting & 0.02 & 0.02 & 0.32 \\
\hline & & Social resting & 0.03 & 0.03 & 0.41 \\
\hline & & Sex & -0.01 & 0.02 & 0.61 \\
\hline \multirow[t]{6}{*}{ (e) Long grunt rate } & \multirow[t]{6}{*}{ ID nested in group } & Intercept & 0.13 & 0.04 & $<0.01$ \\
\hline & & Group movements & 0.14 & 0.05 & $<0.01$ \\
\hline & & Locomotion & 0.14 & 0.04 & $<0.01$ \\
\hline & & Resting & 0.07 & 0.04 & 0.07 \\
\hline & & Social resting & 0.02 & 0.05 & 0.70 \\
\hline & & Sex & -0.12 & 0.05 & $<0.01$ \\
\hline \multirow[t]{7}{*}{ (f) Social interactions } & \multirow[t]{7}{*}{ Dyad nested in group } & Intercept & -4.93 & 1.44 & $<0.001$ \\
\hline & & Grunt (no) & 3.79 & 0.73 & $<0.001$ \\
\hline & & $\operatorname{Sex}(m f)$ & 0.13 & 1.3 & 0.92 \\
\hline & & $\operatorname{Sex}(f m)$ & 0.56 & 1.34 & 0.68 \\
\hline & & Sex (ff) & 1.46 & 1.38 & 0.29 \\
\hline & & Kin & 1.27 & 0.7 & 0.07 \\
\hline & & Age & 1.84 & 0.7 & $<0.01$ \\
\hline
\end{tabular}

primates, which also produce close calls at a higher rate when the risk of becoming separated from group members increases (Radford and Ridley 2008; Suguira 2007; Koda et al. 2008; Ey et al. 2009). Thus, from the sender's perspective, grunts appear to signal the senders' location. However, if grunts indeed may modulate a receiver's tendency to approach or to avoid individuals, is less well understood. Hence, the proximate mechanism driving the close function is not entirely clear, and further playback experiments are required to elucidate the receiver's perspective in this context (Fichtel and Manser 2010).
In social interactions, redfronted lemurs usually grunt while approaching conspecifics and the probability of subsequent aggressive behavior decreased when approaches were accompanied by a grunt. As in baboons and macaques (Bauers 1993; Cheney et al. 1995; Silk et al. 2000), redfronted lemurs may use grunts to communicate their intention to behave peacefully toward others. Contrary to the societies of baboons and macaques, redfronted lemurs exhibit a rather egalitarian social structure with only one male being dominant over other males, no dominance relationship among females and a lack of 


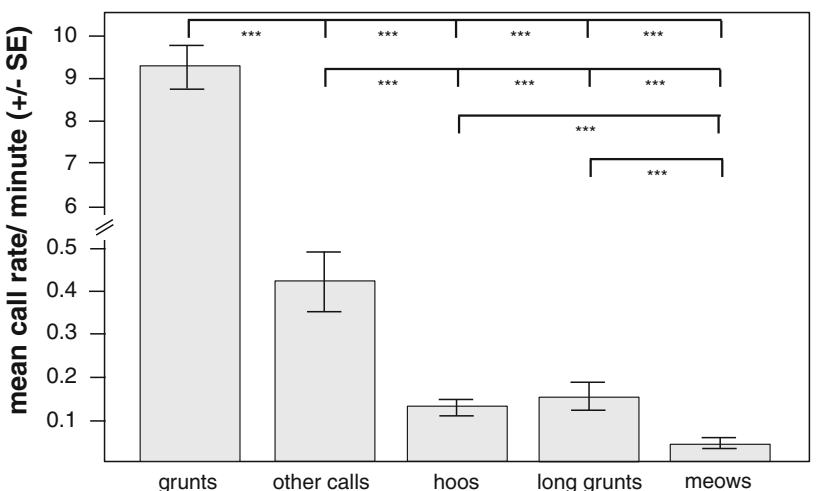

Fig. 2 Mean rates $( \pm \mathrm{SE})$ of grunts, hoos, long grunts and meows. Tukey post hoc comparison: $* * * p<0.001, * * p<0.01$, $* p<0.05$

female dominance (Pereira et al. 1990; Ostner and Kappeler 1999). Consequently, redfronted lemurs are limited in reducing costly conflicts through defined dominance ranks. Since approaches accompanied with grunts resulted more often in affiliative interactions involving grooming, and grooming represents a mechanism to reduce conflicts (Port et al. 2009), the emission of a benign vocal signal might be an even more so important commitment tactic to avoid conflicts. Since high stress levels may have long-term consequences on an individuals' fitness (e.g., Beehner et al. 2005), mechanisms to avoid conflicts are pivotal. Female baboons (Papio ursinus) that received grunts at high frequencies from dominant females had indeed lower glucocorticoid levels (e.g., Crockford et al. 2008). Hence, the use of a benign signal appears to be a crucial mechanism to avoid conflicts and subsequently to reduce stress.

Interestingly, redfronted lemurs responded aggressively in only $16 \%$ of approaches, and, as in other primates aggression was more often directed toward subadults (Pereira and Fairbanks 2002). Although these low agonistic rates reflect the general low agonistic rate in redfronted lemurs (Ostner and Kappeler 1999; Erhart and Overdorff 2008; Pyritz et al. 2011), they may also reflect the effectiveness of using benign vocal signals to avoid conflicts. Another mechanism to reduce conflicts is reconciliation, which has been reported in many anthropoid primates (Aureli and de Waal 2000). Because redfronted lemurs also reconcile soon after a conflict to reduce the probability of further attacks (Kappeler 1993), similar mechanisms of avoiding conflicts have evolved in strepsirrhine and anthropoid primates.
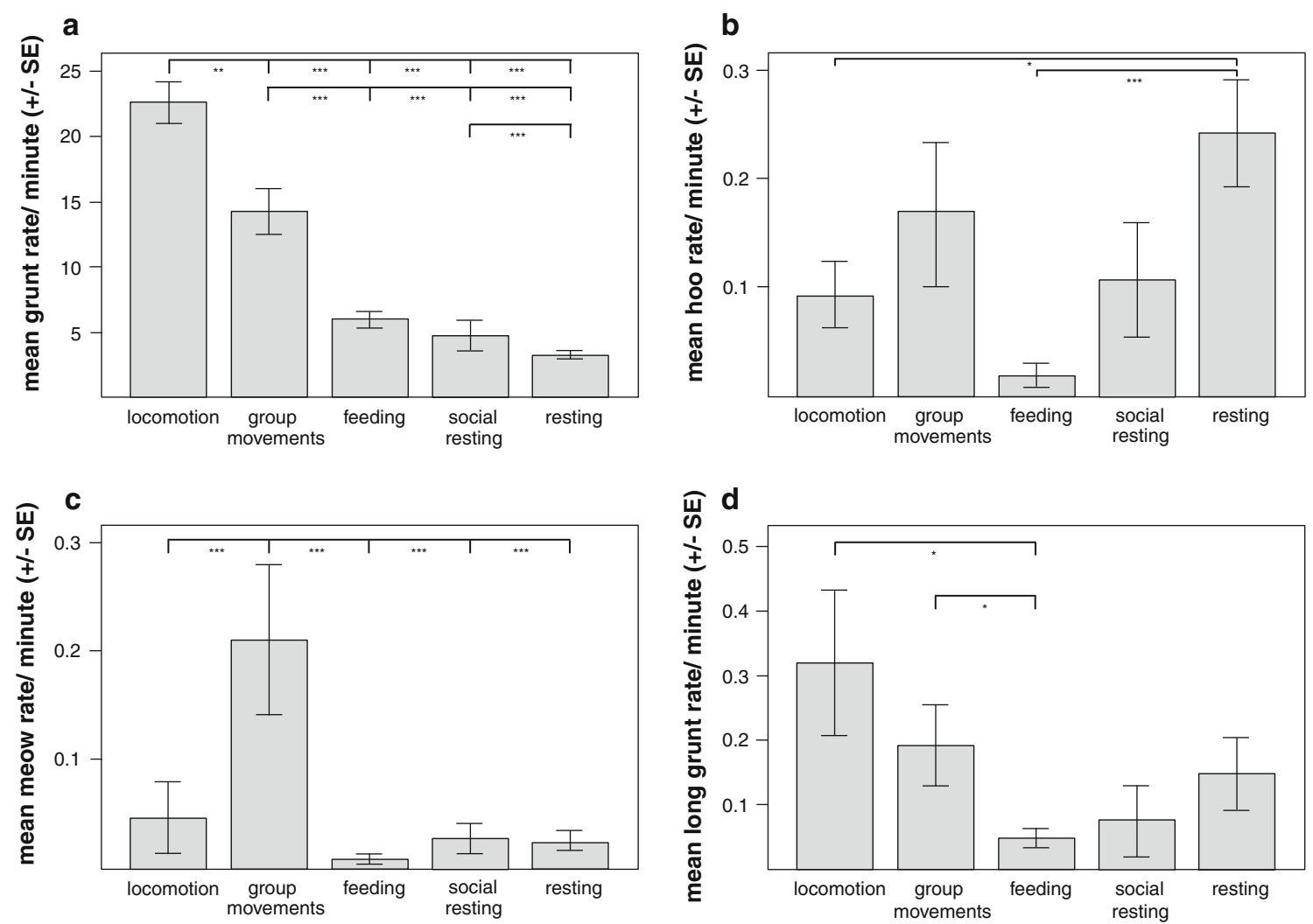

Fig. 3 Mean rates $( \pm \mathrm{SE})$ of a grunts, $\mathbf{b}$ hoos, $\mathbf{c}$ meows and $\mathbf{d}$ long grunts across behavioral contexts. Tukey post hoc comparison: $* * * p<0.001$, $* * p<0.01, * p<0.05$ 


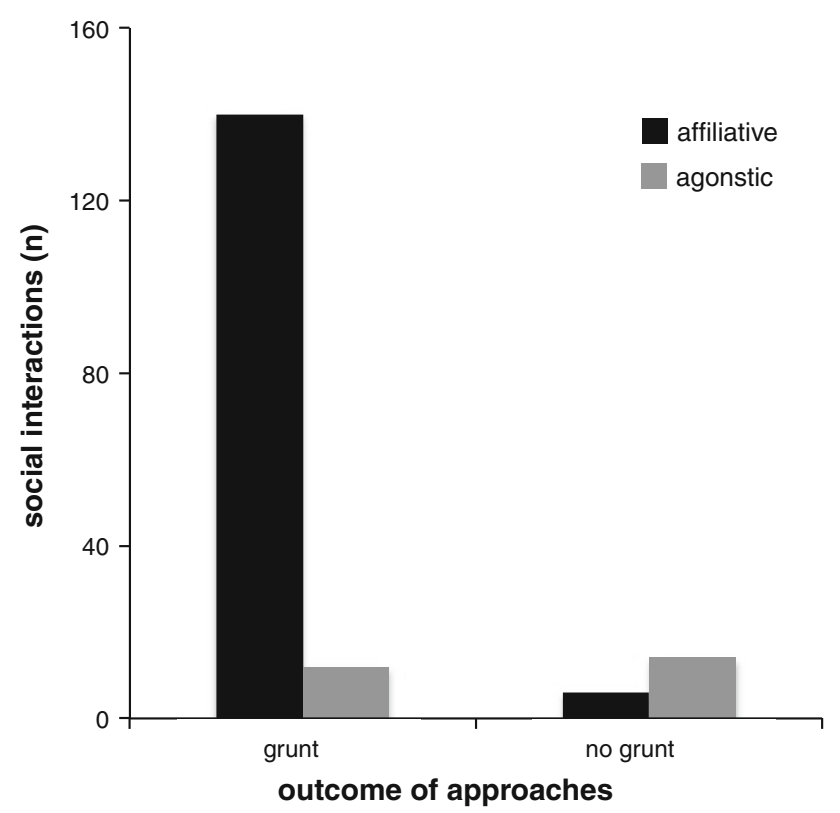

Fig. 4 Frequency of affiliative and agonistic behavior depending on whether approaches were accompanied by grunts or no grunts

Function of long grunts hoos and meows

Long grunts, which are grunts of longer duration than normal grunts (Pereira and Kappeler 1997), are given at relatively low rates but most often while moving. Hoos and meows were in comparison with grunts produced at relatively low rates and in rather specific contexts: hoos during resting and meows during group movements. Hoos are very soft tonal calls, and usually one individual started to produce a hoo whereas one by one others replied with a hoo while continuing to rest. Because in this context redfronted lemurs might be less vigilant, the production of poorly localizable low calls might be advantageous to avoid being discovered by predators through their own vocalizations (Ryan et al. 1981; Fichtel 2009). Meows are also tonal calls but in contrast to hoos higher in frequencies and much louder. Because meows were mainly produced during group movements, when the group is widespread, it might be advantageous to produce a specific call that travels over longer distances to maintain cohesion. Also, closely related ringtailed lemurs (Lemur catta) produce a similar call to maintain cohesion over longer distances (Oda 1996). Thus, as in pygmy marmosets (Cebuella pygmea), the different forms of close calls may degrade differently in the habitat and might be used differentially as a function of how close they were to other conspecifics (de la Torre and Snowdon 2002). However, further studies on the acoustic characteristics of the habitat and degradation of these vocalizations are required. Because other group-living mammals and birds, such as African elephants (Loxodonta africana), bottlenose dolphins (Tursiops truncates), several parrots (Amazona auropalliata, A. albifrons, Aratinga canicularis, Brotogeris jugularis) black-billed gulls (Larus bulleri), or green woodhoopoes (Phoeniculus purpureus), also produce close calls in the context of maintaining group cohesion (Evans 1982; Poole et al. 1988; Janik and Slater 1998; Bradbury 2003; Radford 2004), acoustic signals are a widespread mean in communicative networks to facilitate maintenance of group cohesion and coordination processes (Fichtel and Manser 2010).

In summary, we showed that redfronted lemurs use a combination of context-specific and generic close calls. Grunts, as generic close calls, have a dual function that depends on the audience at which the call is directed. Grunts that appear to be addressed at several targets seem to serve in the maintenance of cohesion, whereas grunts that are addressed at specific targets may serve to signal the benign intent of the approaching animal. Signals of benign intent are low-cost signals of strategic commitment and provide recipients with reliable evidence about the actor's intention and disposition and are effective in facilitating social interactions (Silk et al. 2000; Silk 2002).

This finding is of particular interest, because groupliving in Malagasy primates evolved independently (Kappeler 1999) and they converged with other primates only in the most fundamental ways. However, with regard to mechanisms of conflict management (signals of benign intent and reconciliation; Kappeler 1993), they exhibit comparable complexity as anthropoid primates. Interestingly, lemur's abilities in the domain of social cognition appear to deviate from the better-known anthropoid primates (Fichtel and Kappeler 2010), but recent studies on social learning and the evolution of behavioral traditions (Hosey et al. 1997; Kendal et al. 2010; Fichtel and Kappeler 2011; Schnoell and Fichtel 2012) as well as the results of this study indicate that their degree of social organization and their cognitive abilities in the social domain are not as limited as previously thought (Jolly 1966; Deaner et al. 2006; Fichtel and Kappeler 2010).

Acknowledgments We thank the Département de Biologie Animale, Université d'Antananarivo, and the CAFF of the Direction des Eaux et Forêts and the CNFEREF in Morondava for the authorization and support of this study. This manuscript benefited greatly from statistical support from Cornelia Kraus and from helpful comments by Peter Kappeler and Shannon Digweed as well as 2 anonymous referees.

Open Access This article is distributed under the terms of the Creative Commons Attribution License which permits any use, distribution, and reproduction in any medium, provided the original author(s) and the source are credited.

\section{References}

Alexander RD (1974) The evolution of social behavior. Annu Rev Ecol Evol S 5:325-382 
Altmann J (1974) Observational study of behavior: sampling methods. Behaviour 49:227-267

Aureli F, de Waal FBM (2000) Natural conflict resolution. The University of California Press, Berkeley

Barton RA (1996) Neocortex size and behavioural ecology in primates. Proc R Soc B 263:173-177

Bates D, Maechler M, Dai B (2008) lme4: linear mixed-effects models using S4 classes: $\mathrm{R}$ package version 0.999375-28. http://CRAN.R-project.org/

Bauers KA (1993) A functional analysis of staccato grunt vocalizations in the stumptailed macaques (Macaca fuscata). Ethology 94:147-161

Bearder SK (1987) Lorises, bushbabies, and tarsiers: diverse societies in solitary foragers. In: Cheney DL, Seyfarth RM, Wrangham RW, Struhsaker TT, Smuts BB (eds) Primate societies. University of Chicago Press, Chicago, pp 11-24

Beehner JC, Bergman TJ, Cheney DL, Seyfarth RM, Whitten PL (2005) The effect of new alpha males on female stress in freeranging baboons. Anim Behav 69:1211-1221

Bertram BCR (1978) Living in groups: predators and prey. In: Davies NB, Krebs JR (eds) Behavioural ecology: an evolutionary approach. Blackwell, Oxford, pp 269-285

Biben M (1993) Recognition of order effects in squirrel monkey antiphonal call sequences. Am J Primatol 29:109-124

Boinski S (1993) Vocal coordination of troop movement among white-faced capuchin monkeys, Cebus capucinus. Am J Primatol 30:85-100

Boinski S, Garber P (2000) On the move: how and why animals travel in groups. The University of Chicago Press, Chicago

Boinski S, Moraes E, Kleiman DG, Dietz JM, Baker AJ (1994) Intragroup vocal behaviour in golden lion tamarins, Leontopithecus rosalia: honest communication of individual activity. Behaviour 130:53-75

Bolker BM, Brooks ME, Clark CJ, Geange SW, Poulsen JR, Stevens MHH, White JSS (2009) Generalized linear mixed models: a practical guide for ecology and evolution. Trends Ecol Evol 24:127-135

Bradbury JW (2003) Vocal communication in wild parrots. In: De Waal FBM, Tyack PL (eds) Animal social complexity: intelligence, culture and individualized societies. Harvard University Press, Cambridge, pp 293-316

Cheney DL, Seyfarth RM (1996) The function and mechanism underlying baboon 'contact' barks. Anim Behav 52:507-518

Cheney DL, Seyfarth RM, Silk JB (1995) The role of grunts in reconciling opponents and facilitating interactions among adult female baboons. Anim Behav 50:249-257

Crockford C, Wittig RM, Whitten PL, Seyfarth RM, Cheney DL (2008) Social stressors and coping mechanisms in wild female baboons (Papio hamadryas ursinus). Horm Behav 53:254-265

de la Torre S, Snowdon CT (2002) Environmental correlates of vocal communication of wild pygmy marmosets, Cebuella pygmaea. Anim Behav 63:847-856

Deaner RO, van Schaik CP, Johnson VE (2006) Do some taxa have better domain-general cognition than others? A meta-analysis of nonhuman primate studies. Evol Psychol 4:149-196

Digweed SM, Fedigan LM, Rendall D (2007) Who cares who calls? Selective responses to the lost calls of socially dominant group members in the white-faced capuchin (Cebus capucinus). Am J Primatol 69:829-835

Erhart E, Overdorff D (2008) Rates of agonism by diurnal Lemuroids: implications for female social relationships. Int $\mathrm{J}$ Primatol 29:1227-1247

Evans RM (1982) Foraging — flock recruitment at a black-billed gull colony: implications for the information hypothesis. Auk 99:24-30
Ey E, Rahn C, Hammerschmidt K, Fischer J (2009) Wild female olive baboons adapt their grunt vocalizations to environmental conditions. Ethology 115:493-503

Faraway JJ (2006) Extending the linear model with R. Chapman \& Hall, London

Fichtel C (2009) Costs of alarm calling: lemur alarm calls attract fossas. Lemur News 14:53-55

Fichtel C, Kappeler PM (2002) Anti-predator behavior of groupliving Malagasy primates: mixed evidence for a referential alarm call system. Behav Ecol Sociobiol 51:262-275

Fichtel C, Kappeler PM (2010) Human universals and primate symplesiomorphies: establishing the lemur baseline. In: Kappeler PM, Silk J (eds) Mind the gap: tracing the origins of human universals. Springer, Heidelberg, pp 395-426

Fichtel C, Kappeler PM (2011) Variation in the meaning of alarm calls in Verreaux's and Coquerel's sifakas (Propithecus verreauxi, $P$. coquereli). Int J Primatol 32:346-361

Fichtel C, Manser MB (2010) Vocal communication in social groups. In: Kappeler PM (ed) Animal behaviour: evolution and mechanisms. Springer, Berlin, pp 29-54

Hosey GR, Jacques M, Pitts A (1997) Drinking from tails: social learning of a novel behaviour in a group of ring-tailed lemurs (Lemur catta). Primates 38:415-422

Hothorn T, Bretz F, Westfall P (2008) Simultaneous inference in general parametric models Biometris 50:346-363

Janik VM, Slater PJB (1998) Context-specific use suggests that bottlenose dolphin signature whistles are cohesion calls. Anim Behav 56:829-838

Jolly A (1966) Lemur social behavior and primate intelligence. Science 153:501-506

Kappeler PM (1993) Reconciliation and post-conflict behaviour in ringtailed lemurs, Lemur catta and redfronted lemurs, Eulemur fulvus rufus. Anim Behav 45:901-915

Kappeler PM (1997) Determinants of primate social organization: comparative evidence and new insights from Malagasy lemurs. Biol Rev 72:111-151

Kappeler PM (1999) Convergence and nonconvergence in primate social systems. In: Fleagle J, Janson C, Reed K (eds) Primate communities. Cambridge University Press, Cambridge, pp 158-170

Kappeler PM, Fichtel C (2012a) A 15-year perspective on the social organization and life history of Sifaka in Kirindy Forest. In: Kappeler PM, Watts DP (eds) Long-term field studies of primates. Springer, Berlin

Kappeler PM, Fichtel C (2012b) Female reproductive competition in Eulemur rufifrons: eviction and reproductive restraint in a plurally breeding Malagasy primate. Mol Ecol 21:685-698

Kendal RL, Custance D, Kendal JR, Vale G, Stoinski T, Rakotomalala NI, Rasaminanana H (2010) Evidence for social learning in wild lemurs (Lemur catta). Learn Behav 38:220-234

Koda H, Shimooka Y, Sugiura H (2008) Effects of caller activity and habitat visibility on contact call rate of wild Japanese macaques (Macaca fuscata). Am J Primatol 70:1055-1063

Masataka N (1989) Motivational referents of contact calls in Japanese macaques. Ethology 80:265-273

Oda R (1996) Effects of contextual and social variables on contact call production in free-ranging ringtailed lemurs (Lemur catta). Int J Primatol 17:191-205

Ostner J, Kappeler PM (1999) Central males instead of multiple pairs in redfronted lemurs, Eulemur fulvus rufus (Primates, Lemuridae)? Anim Behav 58:1069-1078

Pereira ME, Fairbanks LA (2002) Juvenile primates: life history, development, and behavior. The University of Chicago Press, Chicago

Pereira ME, Kappeler PM (1997) Divergent system of agonistic behaviour in lemurid primates. Behaviour 134:225-274 
Pereira ME, Kaufman R, Kappeler PM, Overdorff DJ (1990) Female dominance does not characterize all of the Lemuridae. Folia Primatol 55:96-103

Poole JH, Payne K, Langbauer WR Jr, Moss CJ (1988) The social contexts of some very low frequency calls in African elephants. Behav Ecol Sociobiol 22:385-392

Port M, Clough D, Kappeler PM (2009) Market effects offset the reciprocation of grooming in free-ranging redfronted lemurs, Eulemur fulvus rufus. Anim Bev 77:29-36

Pyritz L, Fichtel C, Kappeler PM (2010) Conceptual and methodological issues in the comparative study of collective group movements. Behav Proc 84:681-684

Pyritz LW, Kappeler PM, Fichtel C (2011) Coordination of group movements in wild red-fronted lemurs: processes and influence of ecological and reproductive seasonality. Int $\mathbf{J}$ Primatol 32:1325-1347

Radford AN (2004) Vocal coordination of group movement by green woodhoopoes (Phoeniculus purpureus). Ethology 110:11-20

Radford AN, Ridley AR (2008) Close calling regulates spacing between foraging competitors in the group-living pied babbler. Anim Behav 75:519-527

Rendall D, Seyfarth RM, Cheney DL, Owren MJ (1999) The meaning and function of grunt variants in baboons. Anim Behav 57:583-592

Rendall D, Cheney DL, Seyfarth RM (2000) Proximate factors mediating contact calls in adult female baboons (Papio cynocephalus ursinus) and their infants. J Comp Psychol 114:36-46

Richard AF (1987) Malagasy prosimians: female dominance. In: Smuts BB, Cheney DL, Seyfarth RM, Wrangham RW, Struhsaker TT (eds) Primate societies. University of Chicago Press, Chicago, pp 25-33

Ryan MJ, Tuttle MD, Taft LK (1981) The costs and benefits of frog chorusing behavior. Behav Ecol Sociobiol 8:273-278

Schnoell AV, Fichtel C (2012) Wild redfronted lemurs (Eulemur rufifrons) use social information to learn new foraging techniques. Anim Cogn. doi:10.1007/s10071-012-0477-y
Silk JB (2002) Grunts, girneys and good intentions: the origin of strategic commitment in nonhuman primates. In: Nesse R (ed) Commitment: evolutionary perspectives. Russell Sage Press, New York, pp 138-157

Silk JB, Kaldor E, Boyd R (2000) Cheap talk when interests conflict. Anim Behav 59:423-432

Snowdon CT, Cleveland J, French JA (1983) Responses to contextand individual-specific cues in cotton-top tamarin long calls. Anim Behav 31:92-101

Struhsaker TT (1967) Auditory communication among vervet monkeys (Cercopithecus aethiops). In: Altmann SA (ed) Social communication among primates. University of Chicago Press, Chicago, pp 281-324

Suguira H (2007) Effects of proximity and behavioral context on acoustic variation in the coo calls of Japanese macaques. Am J Primatol 69:1412-1424

Tattersall I (1982) The primates of Madagascar. Columbia University Press, New York

Trillmich J, Fichtel C, Kappeler PM (2004) Coordination of group movements in wild Verreaux's sifakas (Propithecus verreauxi). Behaviour 141:1103-1120

van Schaik CP (1983) Why are diurnal primates living in groups? Behaviour 87:120-144

van Schaik CP, Kappeler PM (1993) Life history, activity period and lemur social system. In: Kappeler PM, Ganzhorn JU (eds) Lemur social system and their ecological basis. Plenum Press, New York, pp 241-260

Whitham JC, Gerald MS, Maestripieri D (2007) Intended receivers and functional significance of grunt and girney vocalizations in free-ranging female rhesus macaques. Ethology 113:862-874

Zemel A, Lubin Y (1995) Inter-group competition and stable group sizes. Anim Behav 50:485-488

Zuur AF, Ieno EN, Walker NJ, Saveliev AA, Smith GM (2009) Mixed effects models and extensions in ecology with $\mathrm{R}$. Springer, New York 